\title{
Prototipe Sistem Pengunci Pintu Melalui Internet Menggunakan Arduino Uno Berbasis Android
}

\section{Prototype of Door Lock System Over the Internet Using Arduino Uno Based on Android}

\author{
Kurniadin Abd. Latif ${ }^{1 *}$, Wahyudi², Azriel Christian Nurcahyo ${ }^{3}$ \\ ${ }^{1}$ Universitas Bumigora \\ ${ }^{2}$ SD Inpres Bontomarinra \\ ${ }^{3}$ Institut Shanti Bhuana \\ kurniadin@universitabumigora.ac.id ${ }^{1 *}$,wahyudisk12@gmail.com², azriel@shantibhuana.ac.id ${ }^{3}$
}

\begin{abstract}
Abstrak - Internet of Think(IoT) muncul sebagai isu besar di Internet, diiharapkan bahwa miliaran hal fisik atau benda akan dilengkapi dengan berbagai jenis sensor terhubung ke internet melalui jaringan serta dukungan teknologi seperti tertanam sensor dan aktualisasi. Penelitian ini bertujuan merancang serta analisis penerapan prototype Sistem Pengunci Pintu Melalui Internet Menggunakan Arduino Uno Berbasis Android. Penelian ini menggunakan metode SDLC dalam melakukan perancangan dan pengembangan prorotype sistem Pengunci Pintu Melalui Internet Menggunakan Arduino Uno Berbasis Android. Terdapat 3 tahapan dari metode SDLC yang digunakan dalam penelitian ini yaitu Analisis Kebutuhan, Desain Sistem dan Implementasi sistem. Inputan dari sistem ini berupa perintah on dan off dari smartphone yang dikirim ke thingspeak sebagai layanan server dan akan dilanjutkan ke perangkat arduino yang telah tersambung selenoid doorlock. Jika pintu dibuka, maka sensor magnetik switch akan mengirim kembali informasi ke thingspeak dan dilanjutkan ke smartphone sebagai feedback. Hasil penerapan bahwa sistem dapat melakukan lock dan unlock pintu jika perangkat sistem terhubung ke internet yang terhubung dengan layanan dari Thingspeak. prototype sistem pengunci pintu ini diimplementasikan pada 2 pintu yang telah terpasang Selemoid doorlock dan sensor magnetic switch. Hasil dari pengujian yang telah dilakukan di jalan mamo 2 pada tanggal 25-08-2016 rata-rata waktu diperlukan untuk lock 4.36 detik dan unlock 5.30 detik, sedangkan pengujian sensor rata-rata waktu yang diperlukan untuk mengirim data sensor dengan kondisi terbuka 12.33 detik dan tertutup 12.43 detik. Waktu delay tergantung pada kondisi jaringan yang terhubung dengan sistem.
\end{abstract}

Kata Kunci: Prototype, Internet of Think, SDLC, Arduino Uno, Selenoid Doorlock

\begin{abstract}
Internet of Think (IoT) is emerging as a big issue on the internet, it is expected that billions of objects will be equipped with various types of sensors connected to the internet through networks as well as technology support such as embedded sensors and actualization. This study aims to design and analyze the application of a prototype door locking system via the internet using Arduino Uno based on Android. This research uses the SDLC method in designing and developing a prototype door lock system over the internet using Arduino Uno based on Android. There are 3 stages of the SDLC method used in this research, namely Requirements Analysis, System Design, and System Implementation. The input from this system is in the form of on and off commands from smartphones that are sent to thingspeak as a server service and will be continued to Arduino devices that have been connected to a solenoid doorlock. If the door is opened, the magnetic sensor switch will send the information back to Thingspeak and continue to the smartphone as feedback. The results of the tests that have been carried out are that the average time required for lock 4.36 seconds and unlock 5.30 seconds, while the average sensor test time required to send sensor data with conditions Open 12.33 seconds and Closed 12.43 seconds. The delay time depends on the condition of the network connected to the system.
\end{abstract}

Keywords: Prototype, Internet of Think, SDLC, Arduino Uno, Selenoid Doorlock

Jurnal Bumigora Information Technology (BITe)

Vol.3, No.1, Juni 2021, pp. 69-81

ISSN: 2685-4066

DOI: 10.30812/bite.v3i1 


\section{Pendahuluan}

Seiring perkembangan jaman yang disertai dengan kemajuan teknologi, cara berpikir manusia pun kini semakin meningkat pula. Manusia dituntut untuk dapat melakukan berbagai aktivitas dengan cepat, sampai kepada banyak hal yang dapat dikotrol dari jarak jauh. Internet of Think (IoT) muncul sebagai isu besar di Internet, diiharapkan bahwa miliaran hal fisik atau benda akan dilengkapi dengan berbagai jenis sensor terhubung ke internet melalui jaringan serta dukungan teknologi seperti tertanam sensor dan aktualisasi, frekuensi radio Identifikasi (RFID), jaringansensor nirkabel, real-time danlayanan web, IOT sebenarnya cyber fisik sistem atau jaringan dari jaringan. Internet of Things (IOT) adalah struktur di mana objek,orang disediakan dengan identitas eksklusif dan kemampuan untukpindah data melalui jaringan tanpa memerlukan dua arahantara manusia ke manusia yaitu sumber ke tujuan atau interaksi manusia ke komputer[1][2]. Internet of Things merupakan perkembangan keilmuan yang sangat menjanjikan untuk mengoptimalkan kehidupan berdasarkan sensor cerdas dan peralatan pintar yang bekerjasama melalui jaringan internet [3][4].

Mengamati dari kehidupan di sekitar masyarakat pada umumnya masih menggunakan cara manual untuk melakukan berbagai kegiatan, salah satunya dalam hal mengunci dan membuka kunci pintu (Lock and Unlock). Pintu manual yang digunakan sekarang memiliki kelemahan, bahkan ada beberapa kejadian dimana orang dapat membuka pintu dengan menggunakan kunci palsu atau kunci T. Selain itu sistem kontrol sekarang ini masih menggunakan sistem kontrol antarmuka. Untuk itu diperlukan pengembangan agar lebih mempermudah pengontrolan tanpa harus berada di sekitar obyek yang dikontrol. Namun macam-macam sistem kontrol yang telah ada pasti memiliki kekurangan dan kelebihan masing-masing.

Terdapat beberapa penelitian yang berkaitan seperti [5] yaitu merancang sistem pengunci pintu otomatis berbasis arduino dengan menggunakan password. Sistem ini menggunakan mikrokontroler arduino sebagai pengendali setiap masukan yang diberikan. Penelitian lainnya oleh [6] yaitu membuat sebuah perangkat sistem Internet of Things (IoT) yang berfungsi untuk mengunci dan membuka lebih dari satu pintu secara bersamaan menggunakan Arduino Mega 2560 R3 (ATMega2560), terhubung dengan internet menggunakan modul Wi-Fi ESP8266. Sistem ini dikontrol melalui browser. Penelitian lainnya oleh [7] yaitu sistem kunci pintu menggunakan RFID dan password berbasis arduino uno dengan one time password melalui sms. Penelitian lainya oleh [8] yaitu melakukan studi aplikasi smartlock pada pintu rumah dengan arduino berbasis iot dengan sensor suara.

Sistem pengontrolan pintu menggunakan aplikasi Android melalui jaringan internet merupakan sistem yang modern dan dirasa cukup efektif untuk pengontrolan pintu, karena kunci pintu tidak akan terbuka apabila aplikasi android tidak terkoneksi dengan mikrokontroller yang telah diatur oleh pemiliknya melalui bantuan programmer atau teknisi. Apabila orang lain ingin masuk keruangan tersebut kunci tidak dapat terbuka sebelum meminta izin pada orang yang memiliki wewenang atas pengontrolan pintu tersebut. Dan dengan cara ini diyakini bisa lebih mempermudah pengontrolan pintu atau ruangan. Berdasarkan masalah dan literatur yang ada, maka peneliti akan melakukan penelitian dan membahas tentang Prototype Sistem Pengunci Pintu Melalui Internet Menggunakan Arduino Uno Berbasis Android.

\section{Metode Penelitian}

Penelian ini menggunakan metode SDLC dalam melakukan perancangan dan pengembangan prorotype sistem Pengunci Pintu Melalui Internet Menggunakan Arduino Uno Berbasis Android. Terdapat beberapa tahapan dari metode SDLC yang digunakan dalam penelitian ini yaitu Analisis, Desain dan Implementasi, dan Testing [9].

\subsection{Analisis}

\subsubsection{Pengumpulan data dan studi pustaka}

Pada perancangan ini dilaksanakan beberapa prosedur dalam menyelesaikan rancangan. Adapun tahapan-tahapannya adalah sebagai berikut:

a. Pengumpulan data dan studi pustaka 
- Pengumpulan data yang dimaksud yaitu peninjauan yang dilakukan secara langsung pada objek kajian, dengan cara melakukan tanya jawab dengan pemilik akun blog yang membahas mengenai perancangan prototype sistem pengunci pintu ini melalui Email

- Studi pustaka yang dimaksud yaitu pengumpulan data dengan membaca dan menelusuri literatur yang berkaitan dengan judul baik yang terdapat pada buku-buku, Skripsi alumni yang masih berkaitan dengan prototype sistem ini maupun dari media informasi seperti ebook, jurnal online kemudian mengambil data yang diperlukan.

\subsection{Desain}

\subsubsection{Diagram Sistem}

Pada pembuatan prototype sistem pengunci pintu ini terdapat beberapa komponen yang saling berkaitan serta mendukung sehingga terbentuk Prototype Sistem Pengunci Pintu Melalui Internet Menggunakan Arduino Uno Berbasis Android. yaitu berupa input, proses, dan output. Untuk lebih jelas dapat dilihat pada gambar dibawah ini.

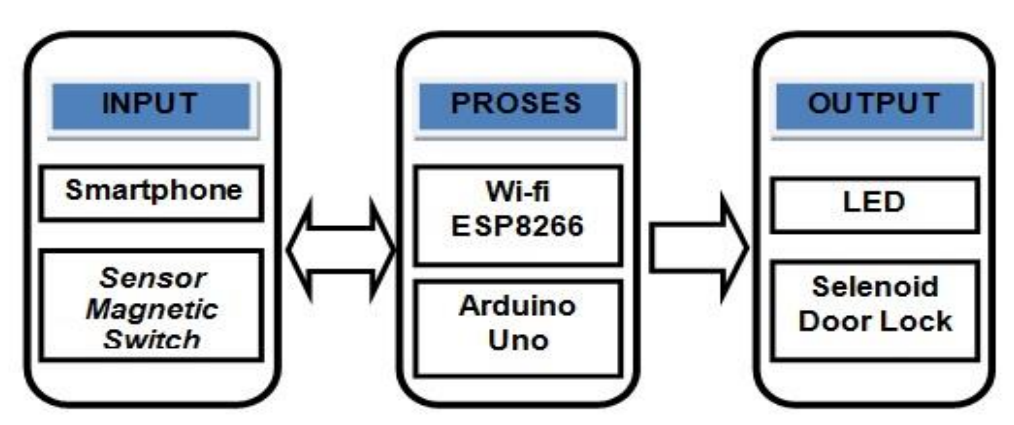

Gambar 1 Diagram blok sistem.

Input dari Sistem Pengunci pintu ini adalah berupa Smartphone Android dan sensor Magnetic Switch. Smartphone Android yang berfungsi sebagai remote untuk membuka kunci dan mengunci pintu sedangkan sensor magnetic switch yang berfungsi sebagai pendeteksi gerakan pintu yang difungsikan sebagai feedback dari pintu ruangan.

Proses dari sistem pengunci pintu ini berupa Arduino Uno sebagai pusat pengontrolan dan ESP8266 yang berfungsi untuk menghubungkan Arduino Uno dengan jaringan internet (thingspeak) supaya dapat melakukan pengiriman dan penerimaan data yang kemudian diproses dan diolah oleh Arduino Uno sesuai yang diprogramkan.

Output dari pengamanan pintu ini adalah berupa gerak dari solenoid doorlock yang membuka dan menutup (lock and Unlock) pintu sesuai yang diprogramkan, dan LED sebagai lampu indikator

\subsubsection{Pembuatan Sistem}

\section{A. Perancangan Rangkaian}

Setelah menentukan spesifikasi sistem, maka tahap selanjutnya adalah melakukan perancangan rangkaian. Hal-hal yang perlu diperhatikan dalam perancangan rangkaian adalah menentukan gambar rangkaian yang akan dibuat dan menentukan komponen dan besarnya tegangan yang diperlukan.

\section{B. Pembuatan Mekanik dan perangkat Keras}

Dalam pembuatan pengunci pintu ini diperlukan rancangan agar pintu dapat bergerak sesuai dengan yang telah ditentukan. Perancangan mekanik ini berupa pembuatan pintu dari bahan kayu agar dapat berfungsi sesuai yang diinginkan. Adapun rancangan pintu dapat ditunjukan pada Gambar 2. 


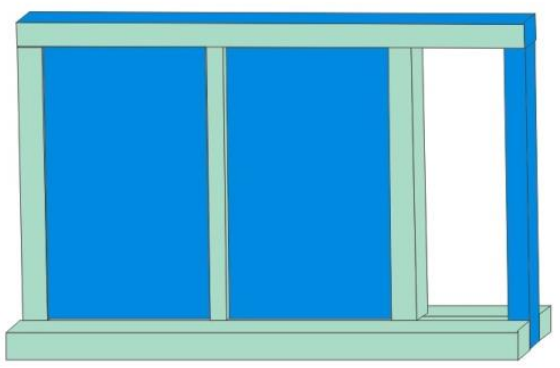

Gambar 2 Rancangan pintu.

Rangkaian yang telah dibuat kemudian disusun komponen sesuai pada tempatnya. Dan kemudian dilakukan pengujian rangkaian, pada tahap ini rangkaian yang telah dibuat akan diuji satu persatu berdasarkan dengan fungsinya masing-masing. Hal ini dilakukan agar satu rangkaian komponen dengan komponen lainnya dapat saling terhubung dengan baik.

\section{Pembuatan Perangkat Lunak}

Pembuatan program Arduino Uno pada Prototype Sistem Pengunci Pintu Melalui Internet Menggunakan Arduino Uno Berbasis Android ini adalah menggunakan bahasa pemrograman C. Bahasa $\mathrm{C}$ adalah bahasa pemrograman tingkat tinggi yang hampir mendekati bahasa manusia. Teks editor yang digunakan untuk membuat bahasa $\mathrm{C}$ adalah Arduino IDE, aplikasi bawaan dari Arduino ini bisa mengupload langsung ke mikrokontroler. Setelah program ditulis kemudian dikompiler agar menjadi bahasa mesin. Adapun Listing Program pengunci pintu menggunakan IDE Arduino dapat tunjukan pada Gambar 3.

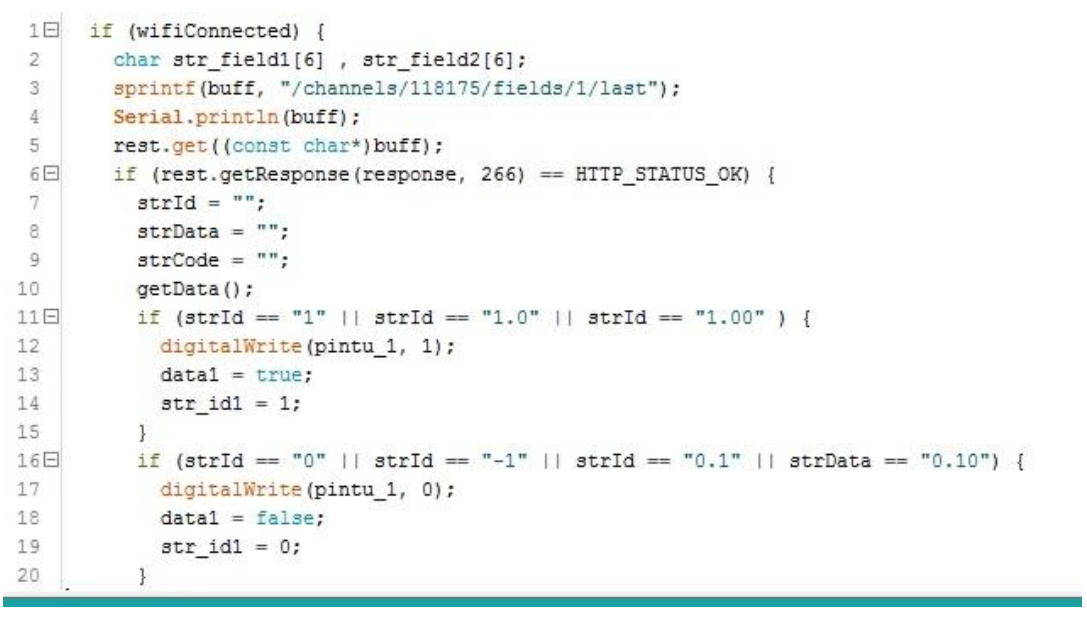

Gambar 3 Listing program pengunci pintu dengan IDE Arduino.

Adapun penjelasan gambar diatas berupa bagian listing program pengunci pintu (solenoid Doorlock) dengan IDE Arduino dimana fungsi "strId" berupa 1, 1.0, 1.00 adalah kondisi solenoid doorlock dalam keadaan unlock sedangkan fungsi "strId" berupa $0,-1,0.1,0.10$ adalah adalah kondisi solenoid doorlock dalam keadaan lock.

Sistem Pengunci Pintu Melalui Internet Menggunakan Arduino Uno Berbasis Android ini adalah menggunakan App Inventor yang digunakan untuk membuat dan mendesain aplikasi Android yang berbasis Web page dan Java Interface. Adapun pembuatan aplikasi android menggunakan App Inventor dapat tunjukan pada Gambar 4. 


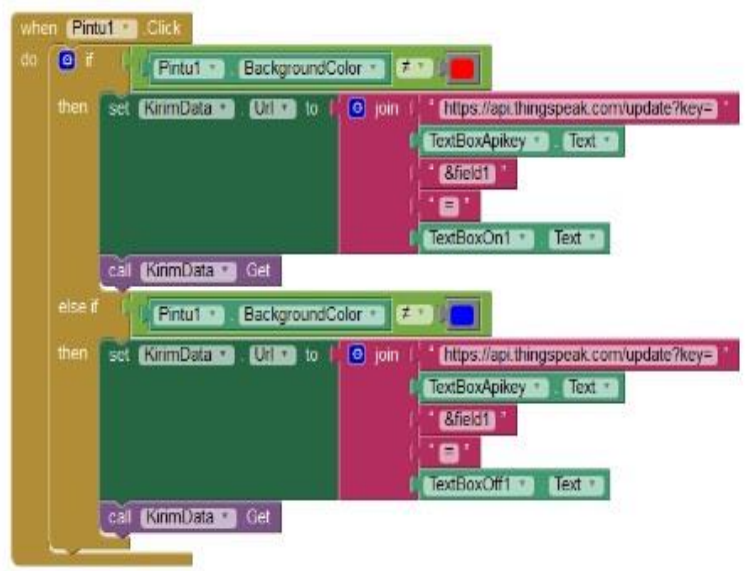

Gambar 4 Pembuatan aplikasi android menggunakan App Inventor.

Adapun penjelasan gambar diatas berupa bagian dari pembuatan apliksai android yang menjelaskan fungsi tombol kontrol yang ada pada aplikasi android apabila ditekan maka data akan dikirim. Selain pembuatan Apliksi terdapat juga proses konfigurasi server untuk IOT yaitu Thingspeak. ThingSpeak adalah layanan platform analitik IoT yang memungkinkan Anda untuk menggabungkan, memvisualisasikan, dan menganalisis aliran data langsung di cloud. Anda dapat mengirim data ke ThingSpeak dari perangkat Anda, membuat visualisasi instan dari data langsung, dan mengirim peringatan [10]. Dalam penelitian ini thinkspeak digunakan sebagai server IoT.

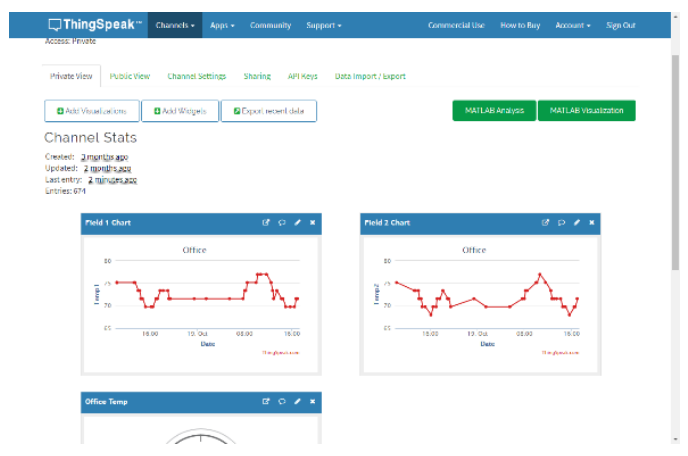

Gambar 5. Thingspeak

\subsubsection{Flowchart Sistem}

Adapun flowchart system dapat ditunjukan pada Gambar 6. 

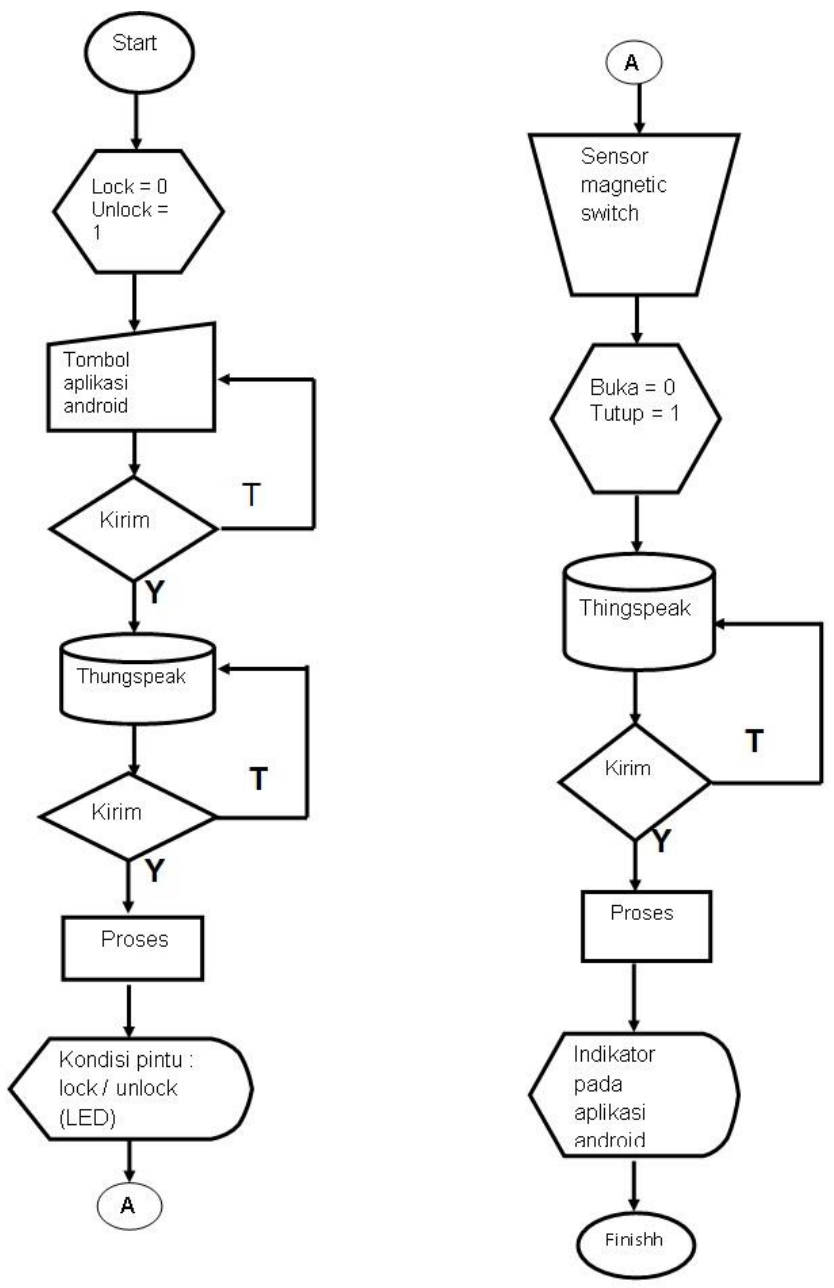

Gambar 6. Flowchart Sistem.

Adapun penjelasan gambar flowchart sistem adalah sebagai berikut:

a. Mulai

b. Inisialisasi nilai lock $=0$ dan unlock $=1$.

c. Tombol aplikasi android ditekan

- Jika Ya : akan mengirim data ke thingspeak untuk lock atau unlock,

- jikaTidak : data tidak terkirim maka tombol harus ditekan lagi sampai aplikasi memberi tanda terkirim.

d. Thingspeak

- Jika Ya : Thingspeak akan mengirim data yang diterima dari aplikasi android ke Rangkaian Sistem dan diproses oleh arduino uno,

- Jika Tidak : maka thingspeak akan mengirim terus secara otomatis.

e. Data diproses oleh arduino

f. Kondisi pintu

Jika ada data yang diterima akan menentukan kondisi pintu dalam keadaan lock dengan indikator LED Off atau unlock dengan indikator LED On sesuai data yang diterima.

g. Sensor magnetic Switch

Jika terjadi perubahan pergerakan pada pintu, maka sensor akan mengirim data ke thingspeak untuk memberikan indicator pada aplikasi android. Jika tidak ada perubahan pergerakan maka tidak ada data yang dikirim.

h. Inisialisasi nilai buka $=0$ dan tutup $=1$ 
i. Thingspeak

- Jika Ya : Thingspeak akan mengirim data yang diterima dari sensor magnetic switch dan diproses oleh arduino uno ke aplikasi android.

- Jika Tidak : maka thingspeak akan mengirim terus secara otomatis.

j. Data diproses oleh arduino.

k. Indikator aplikasi android

Jika ada data yang diterima akan menentukan kondisi indikator pintu pada aplikasi android.

\subsubsection{Konstruksi}

Prototype Sistem Pengunci Pintu Melalui Internet Menggunakan Arduino Uno Berbasis Android ini memenuhi standart pencapaian hasil berdasarkan spesifikasi awal sistem yang telah direncanakan sebelumnya. Adapun pencapaian yang telah dipenuhi adalah sebagai berikut:

a. Pembuatan pengamanan pintu ini secara umum terdiri atas dua bagian utama, yaitu perangkat keras (hardware) dan perangkat lunak (software).

b. Prototype Sistem Pengunci Pintu Melalui Internet Menggunakan Arduino Uno Berbasis Android ini dapat dikatakan berhasil jika solenoid doorlock dapat melakukan tindakan lock dan unlock sesuai perintah yang dikirim melalui Aplikasi android serta sensor magnetic switch dapat mendeteksi pergerakan pintu dan di kirim ke smartphone sebagai feedback

Arduino Uno yang merupakan rangkaian mikrokontroler dalam rangkaian ini digunakan sebagai pusat pengolahan data, dimana akan membaca input dari smartphone dan sensor magnetic switch suara dan password kemudian memberikan instruksi berupa output ke solenoid doorlock berupa lock dan unlock dan sensor magnetic switch berupa indikator.

\section{Hasil dan Pembahasan}

\subsection{Hasil Perancangan Perangkat Keras}

Setelah melalui beberapa tahapan penelitian, meliputi pembuatan rangkaian elektronika, pembuatan mekanik serta pembuatan perangkat lunak (software) maka telah dihasilkan Prototype Sistem Pengunci Pintu Melalui Internet Menggunakan Arduino Uno Berbasis Android.

Adapun hasil pembuatan Prototype Sistem Pengunci Pintu Melalui Internet Menggunakan Arduino Uno Berbasis Android dapat dilihat pada Gambar 7.

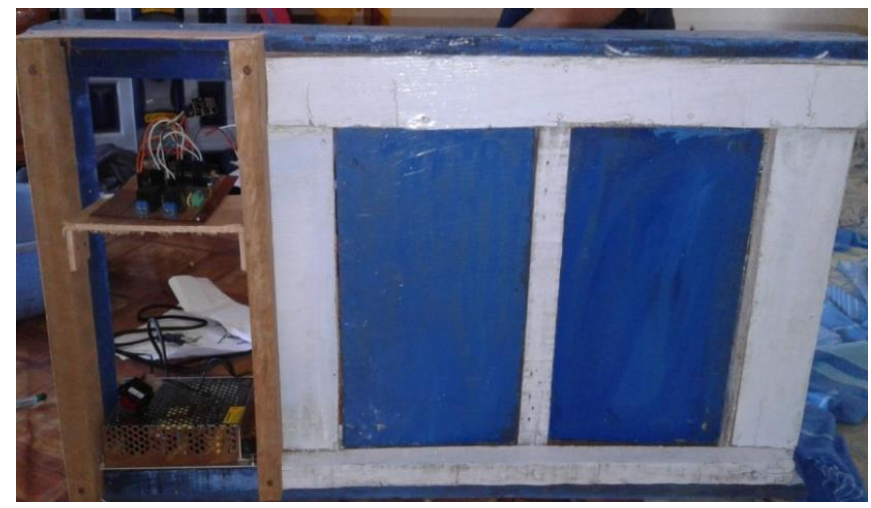

Gambar 7 Prototype Sistem Pengunci Pintu Melalui Internet Menggunakan Arduino Uno Berbasis Android

Gambar diatas merupakan sebuah prototipe dari sistem Sistem Pengunci Pintu Melalui Internet Menggunakan Arduino Uno yang akan dikontrol oleh perangkat android. Prototype tersebut terdiri dari beberapa kompenen seperti arduino uno, ESP8266, relay, selenoid doorlock, magnetic, power switch supplay dan lainnya yang saling terhubung satu sama lain. Adapun gambar skema rangkaian dapat dilihat pada Gambar 8.

https://journal.universitasbumigora.ac.id/index.php/bite

ISSN: 2685-4066 


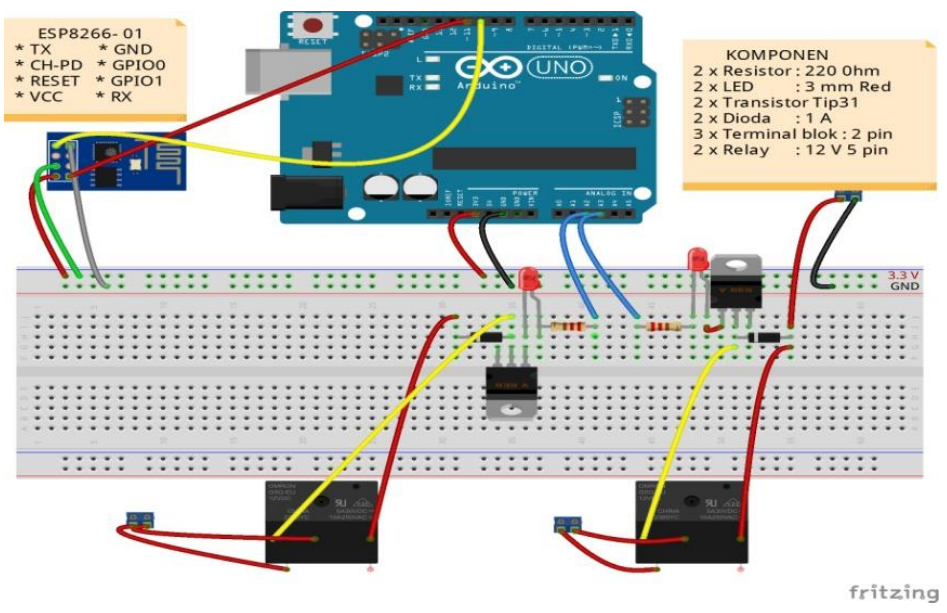

Gambar 8 Skema Rangkaian elektronika

Gambar 8 merupakan kumpulan komponen dari prototype sistem pengunci pintu melalui internet menggunakan arduino uno yang saling terhubung satu sama lain. Selain itu terdapat perangkat yang digunakan sebagai remote pengtrol pengunci pintu yaitu perangkat android. Dari aplikasi tersebut dirancang sebuah aplikasi remote. Adapun hasil aplikasi android dapat dilihat pada Gambar 9.

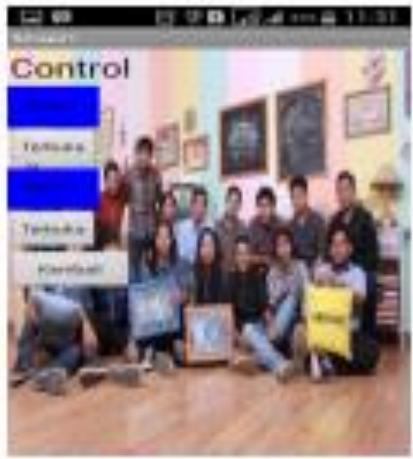

a. Tampilan menu

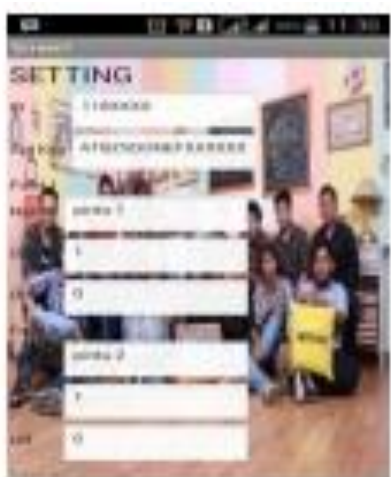

b. Tampilan konfigurasi

Gambar 9. Tampilan aplikasi remote

Gambar 9 tampilan a merupkan tampilan menu control dimana tombol pintu berwarna biru menandakan pintu dalam keadaan lock dan tombol pintu berwarna merah menandakan pintu dalam keadaan unlock. Sedangkan Gambar 9 tampilan b merupakan tampilan mengenai pengaturan aplikasi sebelum melakukan pengontrolan diantaranya Channel ID, Apekey, nama field dan perintah on/off.

\subsection{Analisis Sistem}

Pada pembahasan ini dapat dijelaskan melalui gambar arsitektur sistem di bawah ini. 


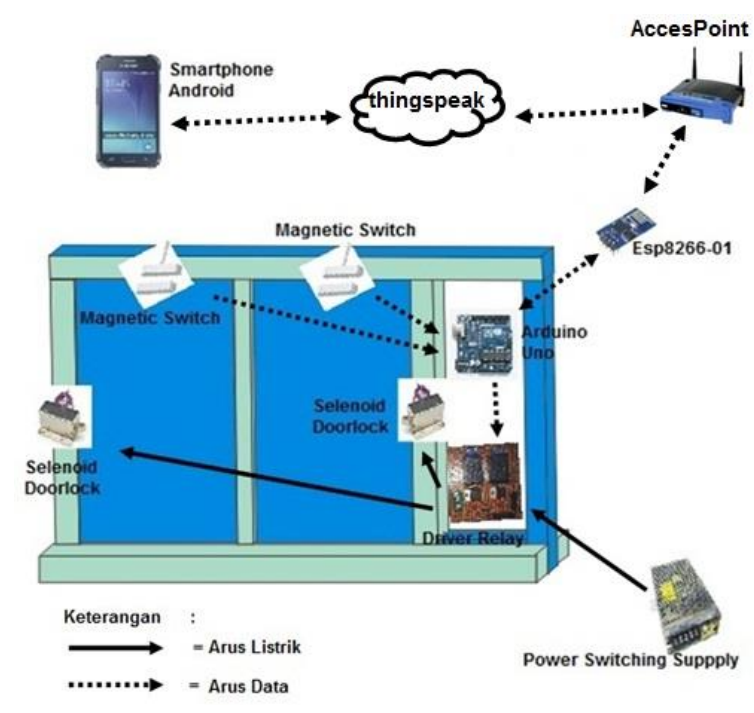

Gambar 10 Arsitektur Sistem berikut:

Berdasarkan pada Gambar 10 maka dapat diberikan keterangan diantaranya sebagai

a. Arduino Uno yang berfungsi mengolah data input sensor, ESP8266 dan output solenoid doorlock

b. Selenoid Doorlock berfungsi sebagai lock dan Unlock atau output.

c. Sensor magnetic switch berfungsi sebagai feedback ketika pintu dibuka atau ditutup.

d. ESP8266 berfungsi sebagai penghubung Arduino Uno ke internet atau thingspeak. Dimana ESS8266 telah diganti firmwarenya dengan cara flashing menggunakan firmware terbaru yang bisa koneksi ke server thingspeak atau internet, sehingga dari flashing firmware inilah didapatkan MAC Addres : 18:FE:34:82:C9:36 dan Pada saat Esp8266 Terkoneksi dengan ke jaringan maka Esp8266 akan mendapatkan IP Addres : 192.168.43.114.

e. Acces Point berfungsi sebagai sumber atau pemancar jaringan (hotspot) yang digunakan oleh ESP8266 untuk terhubung ke server thingspeak atau internet.

f. Thingspeak merupakan suatu server dari Internet Of Things yang menyediakan ruang atau tempat untuk melakukan pengontrolan jarak jauh dengan menggunakan ID Channel dan ApiKey yang telah disediakan sebagai hak akses ke server.

g. Smartphone berfungsi sebagai remote atau input untuk lock dan Unlock solenoid doorlock yang ada pada pintu, Smartphone yang digunakan adalah yang menggunakan OS Android.

h. Driver relay berfungsi untuk menyambung dan memutus arus listrik atau saklar automekanik.

i. Switching Power Supply yang berfungsi sebagai pengubah tegangan listrik sesuai yang dibutuhkan rangkaian.

Pada Sistem ini aplikasi android akan mengirim data ke Arduino Uno melalui internet dengan perantara ESP8266 sebagai penghubung Arduino Uno ke internet melalui Wi-fi, kemudian data diolah oleh Arduino Uno menjadi keluaran berupa gerakan lock dan Unlock pada Selenoid Doorlock dan pintu dapat dibuka maupun ditutup, kemudian sensor magnetic switch akan megirim data ke Arduino Uno untuk diolah dan dikirim ke aplikasi android melalui internet dengan perantara ESP8266. Dari setiap proses input dan output memiliki waktu delay sesuai kekuatan jaringan internet yang terkoneksi.

\subsection{Indikator Kinerja}

Prototype Sistem Pengunci Pintu Melalui Internet Menggunakan Arduino Uno Berbasis Android telah memenuhi standart pencapaian hasil berdasarkan alur system yang telah 
direncanakan sebelumnya. Adapun spesifikasi pencapaian hasil yang telah terpenuhi adalah sebagai berikut :

a. Pembuatan Prototype Sistem Pengunci Pintu Melalui Internet Menggunakan Arduino Uno Berbasis Android secara umum terdiri atas dua bagian utama, yaitu perangkat keras (hardware) dan perangkat lunak (software).

b. Prototype Sistem Pengunci Pintu Melalui Internet Menggunakan Arduino Uno Berbasis Android dapat dikatakan berhasil jika penguncian pintu dapat dilakukan secara jarak jauh melalui aplikasi android.

c. Arduino uno digunakan sebagai pusat pengontrolan dimana akan membaca input dari Aplikasi android dan sensor magnetic switch kemudian memberikan output berupa LED dan indicator aplikasi android.

d. Sensor magnetic switch dapat memberikan input ke arduino uno jika mendeteksi pergerakan pintu yang tealh ditentukan dalam program.

\subsection{Pengujian}

\subsubsection{Pengujian Koneksi WiFi}

Pada pengujian ini, dilakukan pengujian koneksi, dimana Aplikasi Android tidak terhubung ke internet, sehingga Aplikasi android Tidak berfungsi dan mengalami Peringatan Error. Adapun tampilan error dapat dilihat pada Gambar 11.

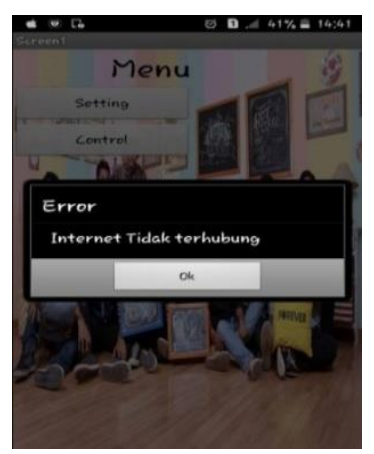

Gambar 11 Tampilan Error Koneksi.

Adapun tampilan aplikasi android terhubung ke internet dapat dilihat pada Gambar 12.

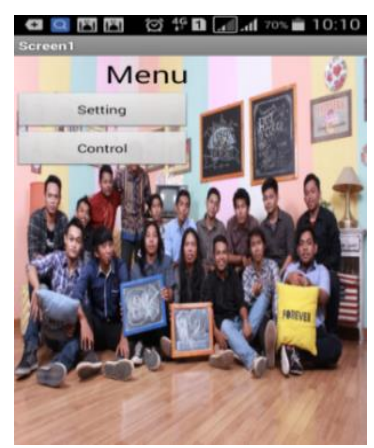

Gambar 12 Tampilan koneksi sukses

\subsubsection{Pengujian Keseluruhan Sistem}

Pada pengujian ini dilakukan dengan menggunakan Aplikasi Android, dimana aplikasi android mengirim data ke Solenoid Doorlock untuk melakukan lock dan unlock pada pintu. Adapun hasil pengujian fungsi aplikasi android dapat dilihat pada Tabel 1. 
Tabel 1 Pengujian Aplikasi android

\begin{tabular}{cccccc}
\hline $\begin{array}{c}\text { Aplikasi } \\
\text { Android }\end{array}$ & Perintah & $\begin{array}{c}\text { Warna } \\
\text { tombol }\end{array}$ & $\begin{array}{c}\text { Kondisi } \\
\text { Pintu }\end{array}$ & $\begin{array}{c}\text { Waktu } \\
\text { (detik) }\end{array}$ & Keterangan \\
\hline Pintu 1 & ON & Merah & Unlock & 4.38 & Berhasil \\
Pintu 1 & OFF & Biru & Lock & 5.87 & Berhasil \\
Pintu 2 & ON & Merah & Unlock & 5.24 & Berhasil \\
Pintu 2 & OFF & Biru & Lock & 7.45 & Berhasil \\
Pintu 1 & ON & Merah & Unlock & 2.31 & Berhasil \\
Pintu 1 & OFF & Biru & Lock & 1.14 & Berhasil \\
Pintu 2 & ON & Merah & Unlock & 9.29 & Berhasil \\
Pintu 2 & OFF & Biru & Lock & 3.21 & Berhasil \\
\hline
\end{tabular}

Dari Tabel 1 pengujian prototype dilakukan dengan cara antara lain :

1. Tombol pintu 1 dengan perintah $\mathrm{ON}$ maka warna tombol akan berwarna merah dan solenoid pada pintu melakukan unlock dengan waktu 4.38 detik dinyatakan berhasil.

2. Tombol pintu 1 dengan perintah OFF maka warna tombol akan berwarna biru dan solenoid pada pintu melakukan lock dengan waktu 5.87 detik dinyatakan berhasil..

3. Tombol pintu 2 dengan perintah $\mathrm{ON}$ maka warna tombol akan berwarna merah dan solenoid pada pintu melakukan unlock dengan waktu 4.24 detik dinyatakan berhasil..

4. Tombol pintu 2 dengan perintah OFF maka warna tombol akan berwarna biru dan solenoid pada pintu melakukan lock dengan waktu 7.45 detik dinyatakan berhasil..

5. Tombol pintu 1 dengan perintah ON maka warna tombol akan berwarna merah dan solenoid pada pintu melakukan unlock dengan waktu 2.31 detik dinyatakan berhasil.

6. Tombol pintu 1 dengan perintah OFF maka warna tombol akan berwarna biru dan solenoid pada pintu melakukan lock dengan waktu 1.14 detik dinyatakan berhasil..

7. Tombol pintu 2 dengan perintah $\mathrm{ON}$ maka warna tombol akan berwarna merah dan solenoid pada pintu melakukan unlock dengan waktu 9.29 detik dinyatakan berhasil..

8. Tombol pintu 2 dengan perintah OFF maka warna tombol akan berwarna biru dan solenoid pada pintu melakukan lock dengan waktu 3.21 detik dinyatakan berhasil..

Rata-rata waktu diperlukan untuk lock 4.36 detik dan unlock 5.30 detik. Pada pengujian sensor magnetic switch terhadap Aplikasi Android, dimana sensor magnetic switch akan mengirim data ke Aplikasi Android.

Adapun hasil pengujian fungsi sensor magnetic switch terhadap aplikasi android yang telah dilakukan dapat dilihat pada Tabel 2.

Tabel 2 Pengujian Sensor Magnetic Switch

\begin{tabular}{ccccc}
\hline Sensor & $\begin{array}{c}\text { Kondisi } \\
\text { Pintu }\end{array}$ & $\begin{array}{c}\text { Hasil Aplikasi } \\
\text { Android }\end{array}$ & $\begin{array}{c}\text { Waktu } \\
\text { (detik) }\end{array}$ & Keterangan \\
\hline Sensor 1 & Buka & Terbuka & 10.25 & Berhasil \\
Sensor 1 & Tutup & Tertutup & 10.87 & Berhasil \\
Sensor 2 & Buka & Terbuka & 13.43 & Berhasil \\
Sensor 2 & Buka & Terbuka & 15.26 & Berhasil \\
Sensor 1 & Buka & Terbuka & 10.35 & Berhasil \\
Sensor 1 & Tutup & Tertutup & 10.04 & Berhasil \\
Sensor 2 & Buka & Terbuka & 15.30 & Berhasil \\
Sensor 2 & Buka & Terbuka & 13.56 & Berhasil \\
\hline
\end{tabular}

Dari Tabel 2 pengujian prototype dilakukan dengan cara antara lain :

1. Sensor $1 /$ pintu 1 dibuka maka indikator pada Aplikasi Android akan menampilkan Terbuka dengan waktu 10.25 detik dinyatakan berhasil.. 
2. Sensor $1 /$ pintu 1 ditutup maka indikator pada Aplikasi Android akan menampilkan Tertutup dengan waktu 10.87 detik dinyatakan berhasil..

3. Sensor 2 / pintu 2 dibuka maka indikator pada Aplikasi Android akan menampilkan Terbuka dengan waktu 13.43 detik dinyatakan berhasil..

4. Sensor 2 / pintu 2 ditutup maka indikator pada Aplikasi Android akan menampilkan Tertutup dengan waktu 15.26 detik dinyatakan berhasil.

5. Sensor $1 /$ pintu 1 dibuka maka indikator pada Aplikasi Android akan menampilkan Terbuka dengan waktu 10.35 detik dinyatakan berhasil..

6. Sensor 1 / pintu 1 ditutup maka indikator pada Aplikasi Android akan menampilkan Tertutup dengan waktu 10.04 detik dinyatakan berhasil..

7. Sensor 2 / pintu 2 dibuka maka indikator pada Aplikasi Android akan menampilkan Terbuka dengan waktu 15.30 detik dinyatakan berhasil..

8. Sensor 2 / pintu 2 ditutup maka indikator pada Aplikasi Android akan menampilkan Tertutup dengan waktu 13.56 detik dinyatakan berhasil..

Rata-rata waktu yang diperlukan untuk mengirim data sensor dengan kondisi Terbuka $=$ 12.33 detik dan Tertutup $=12.43$ detik.

\section{Kesimpulan}

Dari hasil peneletian dan pembahasan pada pembuatan prototype sistem pengunci yang telah dilakukan, maka dapat ditarik kesimpulan yaitu prototype sistem pengunci pintu dibuat dengan memanfaatkan aplikasi android sebagai remote dan sensor magnetic switch sebagai feedback yang memberi indikator pada aplikasi android. Sistem dapat melakukan lock dan unlock pintu jika perangkat sistem terhubung ke internet yang terhubung dengan layanan dari Thingspeak. prototype sistem pengunci pintu ini diimplementasikan pada 2 pintu yang telah terpasang Selemoid doorlock dan sensor magnetic switch. Hasil dari pengujian yang telah dilakukan, rata-rata waktu diperlukan untuk lock 4.36 detik dan unlock 5.30 detik, sedangkan pengujian sensor rata-rata waktu yang diperlukan untuk mengirim data sensor dengan kondisi Terbuka 12.33 detik dan Tertutup 12.43 detik. Waktu delay tergantung pada kondisi jaringan yang terhubung dengan sistem.

\section{Ucapan Terima Kasih}

Judul untuk ucapan terima kasih dan referensi tidak diberi nomor. Terima kasih disampaikan kepada Tim BITe yang telah meluangkan waktu untuk membuat template ini.

\section{Referensi}

[1] A. W. Burange and H. D. Misalkar, "Review of Internet of Things in development of smart cities with data management \& privacy," Conference Proceeding - 2015 International Conference on Advances in Computer Engineering and Applications, ICACEA 2015, pp. 189-195, 2015, doi: 10.1109/ICACEA.2015.7164693.

[2] J. Budiarto and S. Hadi, "Sistem Kendali Peralatan Elektronik Rumah Tangga Berbasis Internet Of Things Menggunakan Protokol MQTT Jurnal BITe : Jurnal Bumigora Information Technology Jurnal BITe : Jurnal Bumigora Information Technology,” vol. 2, no. 1, pp. 1-11, 2020, doi: 10.30812/bite.v2i1.799.

[3] S. L. Keoh, S. S. Kumar, and H. Tschofenig, "Securing the internet of things: A standardization perspective," IEEE Internet of Things Journal, vol. 1, no. 3, pp. 265275, 2014, doi: 10.1109/JIOT.2014.2323395.

[4] P. A. Wulandari, P. Rahima, and S. Hadi, "Rancang Bangun Sistem Penyiraman Otomatis Berbasis Internet of Things Pada Tanaman Hias Sirih Gading," Jurnal Bumigora Information Technology (BITe), vol. 2, no. 2, pp. 77-85, 2020, doi: 10.30812/bite.v2i2.886.

[5] W. Subawani, "Sistem Pengunci Pintu Otomatis Berbasis Arduino Menggunakan Password," Engineering and Technology International Journal, vol. 1, no. 01, pp. 67-

https://journal.universitasbumigora.ac.id/index.php/bite

ISSN: 2685-4066 
76, 2019.

[6] I. P. B. E. Permadi, A. B. Gumelar, and A. Widodo, "Sistem Pengunci Multi Pintu dengan Mikrokontroler Arduino Mega 2560 R3," Jetri : Jurnal Ilmiah Teknik Elektro, vol. 17, no. 1, p. 47, 2019, doi: 10.25105/jetri.v17i1.4445.

[7] A. G. Aditya, I. P. Solihin, and Y. Widiastiwi, "Sistem Kunci Pintu Rfid Dan Password Berbasis Arduino," pp. 81-91, 2020.

[8] D. Gultom, M. F. Susanto, and K. Kunci, "Studi Aplikasi Smartlock Pada Pintu Rumah Dengan Arduino Berbasis Iot Dengan Sensor Suara," Prosiding Industrial Research Workshop and National Seminar, vol. 11, pp. 26-27, 2020.

[9] B. Asmanto, Mustika, and A. Tria, "Implementasi Metode SDLC Pada Aplikasi Pengolahan Data Laporan Bulanan Kegiatan Puskesmas," Jsai, vol. 3, no. 1, pp. 2614 $3062,2020$.

[10] thingspeak.com, “Thingspeak," 2021. . 